\title{
Degradação da paisagem norte-paranaense: \\ um estudo de fragmentos florestais
}

\section{Degradation of the northern paraná landscape: a study on forest fragments}

\author{
Amarildo Souza de Paula'; Efraim Rodrigues $^{2}$
}

Resumo

Devido ao rápido processo de ocupação, quase toda cobertura vegetal nativa do Norte do Paraná foi devastada. Considerando a necessidade de estudos básicos que dêem suporte ao manejo de remanescentes florestais, este trabalho estuda a fragmentação florestal da paisagem num transecto de $180 \mathrm{~km}$ (entre Jacarezinho e Maringá). Adotou-se a hipótese de que a paisagem mais a oeste - colonizada a partir de 1930 (Londrina) e 1947 (Maringá) - sofreu menor degradação antrópica, em comparação a paisagem, situada mais à leste (colonizada em meados do século XIX e início do século XX). Os resultados demonstraram que a hipótese inicial deve ser refutada. Fatores históricos e socioeconômicos influenciaram o modo de ocupação e conseqüentemente, a distribuição dos fragmentos florestais na paisagem.

Palavras chave: Desmatamento, ecologia; sensoriamento remoto

\begin{abstract}
Due to a fast occupation process, nearly all of the native vegetal covering of northern Paraná was devastated. Considering the lack of basic studies that support the management of forest remainders, this dissertation studies the forest fragmentation of the landscape in a transect of $180 \mathrm{~km}$ (between Maringá and Jacarezinho), considering a time and/or age of occupation gradient. One has adopted the hypothesis that the landscape to west, colonized from 1930 (Londrina) and 1947 (Maringá), suffered smaller degradation in a comparison with what happened in the landscape situated further to east (and colonized in the mid $19^{\text {th }}$ century and early $20^{\text {th }}$ century). Results demonstrated that the initial hypothesis should be refute. Historical and factors socioeconomic influenced the occupation way and, consequently, the distribution of the forest fragments in the landscape.
\end{abstract}

Key words: Deforestation, ecology; remote sensing.

1 Eng. Agr., aluno do Programa Pós-Graduação Nível de Mestrado em Agronomia da UEL - Londrina, PR. E-mail: ediama@uol.com.br

2 Eng. Agr., Ph.D.,(professor do Programa Pós-Graduação Nível de Mestrado em Agronomia da UEL - Londrina, PR. E-mail: efraim@uel.br.

* Autor para correspondência. 


\section{Introdução}

Os fragmentos florestais são resultado de diferentes histórias de perturbação da vegetação, nas quais interagiram, ao longo do tempo, fatores inúmeros e diversos (ARAGAKI, 1997).

Presente em todas as etapas da ocupação territorial no país - desde as mais antigas, na Mata Atlântica nordestina, até as atuais nas áreas de cerrado do Centro-Oeste e nas florestas úmidas da Amazônia - a fragmentação florestal é um fenômeno grave, resultante do processo de expansão da fronteira agrícola no Brasil (VIANA; TABANEZ; MARTINEZ, 1992). Vastas paisagens, outrora cobertas por maciços contínuos de vegetação, vêm tomando novas características e constituindo mosaicos diferenciados, onde a vegetação nativa é relegada à condição de ilhas de diferentes tamanhos e formas.

De acordo com Viana (1990), um fragmento florestal é qualquer área de vegetação natural contínua, interrompida por barreiras antrópicas (estradas, cidades, culturas agrícolas, pastagens etc.) ou naturais (montanhas, lagos, outras formações vegetacionais etc.), capazes de diminuir significativamente o fluxo de animais, pólen e/ou sementes. É, portanto, produto de uma ação natural ou antrópica.

Para Ishihata (1999), a fragmentação é a separação artificial do hábitat em fragmentos espacialmente isolados e envolvidos por uma matriz altamente modificada ou degradada, que pode ser constituída por culturas agrícolas ou outro tipo de uso do solo. De acordo com a autora, a fragmentação é um processo resultante da ação antrópica, que possui dois componentes: a) redução da área de um hábitat grande e contínuo, e, b) divisão do hábitat remanescente em fragmentos menores, mais isolados numa matriz de hábitat diferente do original, podendo ser uma paisagem altamente modificada ou degradada, de culturas agrícolas ou outro uso do solo.

As conseqüências da fragmentação florestal são: diminuição da diversidade biológica, redução da área de ecossistemas naturais, distúrbio no regime hidrológico das bacias hidrográficas, mudanças climáticas, erosão do solo, inundações e assoreamento das bacias hídricas, degradação dos recursos naturais, favorecimento ao estabelecimento de espécies invasoras, e, ainda, mudanças nos fluxos químicos e físicos da paisagem, incluindo os movimentos de calor, vento, água e nutrientes (OLIVEIRA et al., 1997; VIANA, 1990; VIANA; TABANEZ; MARTINEZ, 1992; RODRIGUES, 1993; RODRIGUES; CAMARA; DIAS, 1995; ARAGAKI, 1997; SILVA et al., 1997; TABANEZ; VIANA; DIAS, 1997; ISHIHATA, 1999).

A paisagem nativa do Paraná já foi largamente dominada por florestas, que, segundo Maack (1981) cobriam uma área de $176.737 \mathrm{~km}^{2}$ equivalente a $85 \%$ do território do Estado (os 15\% restantes eram várzeas e campos). Conforme Zani (1997), $100.457 \mathrm{~km}^{2}$ eram cobertos por "matas de lei" - rica em peroba (Aspidosperma polyneuron M. Arg.) e outras madeiras de valor -, e $76.280 \mathrm{~km}^{2}$ de mata de pinheiro (Araucaria angustifolia, Bert O. Ktze).

Estimativas do SEMA/IAP/DIDEF em 1997, apontam que as áreas de florestas do território paranaense reduziram-se a apenas $8,59 \%$, sendo representados por fragmentos que precisam ser preservados.

A cobertura florestal nativa da região Norte do Paraná foi reduzida de 84\% em 1900 (FUNDAÇÃO S.O.S MATA ALTÂNTICA/INPE, 2001) para 6,86\% em 1980 (RODRIGUES, 1993), terminando com a continuidade da vegetação original na escala regional e causando mudanças ambientais em grande escala, como incêndios e erosão do solo.

O atual estágio de degradação resulta de um processo histórico de ocupação da terra no Estado. Nos últimos 50 anos, o incentivo ao desmatamento para a extração de madeira e a expansão de fronteira agrícola ganhou proporções ainda maiores. Dos remanescentes das grandes florestas, $40 \%$ estão concentrados em áreas protegidas do Litoral e do ExtremoOeste (Parque Nacional do Iguaçu). Outras áreas, como parques e reservas estaduais, abrangem pouco mais de 1\% do Estado. 
Entre 1960 e 1970, a região Norte do Paraná perdeu 586.740 ha de matas nativas e 18.939 ha de matas plantadas (CARVALHO, 1991).

Considerando a importância de estudos básicos, que dêem suporte às ações de manejo nos remanescentes florestais, neste trabalho adotou-se como hipótese, que a paisagem ao oeste, do rio Tibagi, Norte Novo, colonizada a partir de 1930 (Londrina) e 1947 (Maringá), sofreu uma menor degradação antrópica, em comparação ao que ocorreu na paisagem a leste do rio Tibagi, Norte Velho, colonizada entre o final do século XIX e início do século XX.

\section{Material e Métodos}

A região de estudo esta localizada na região Norte do Paraná, delimitada pêlos rios Itararé, Paranapanema, e Ivaí Dividida em duas áreas, segundo a época e origem da colonização: a) Norte Velho e/ ou Pioneiro, colonizado entre 1860 e 1925, estendese do rio Itararé até a margem direita do rio Tibagi; b) Norte Novo, colonizado entre 1920 e 1950, delimitado pelos rios Tibagi, Ivaí e Paranapanema (CANCIÁN, 1977; LUZ, 1980; PADIS, 1981). Delimitada pelas coordenadas $23^{\circ} 09^{\prime} 24^{\prime \prime} \mathrm{S}, 23^{\circ} 25^{\prime} \mathrm{S}$, 49 $58^{\prime} 16^{\prime \prime} \mathrm{W}$ e $51^{\circ} 57^{\prime} \mathrm{W}$, abrange os municípios de 1- Jacarezinho, 2- Santa Mariana, 3- Uraí, 4- Londrina,5-Cambé, 5- Sabáudia e 6- Maringá (Figura 1).

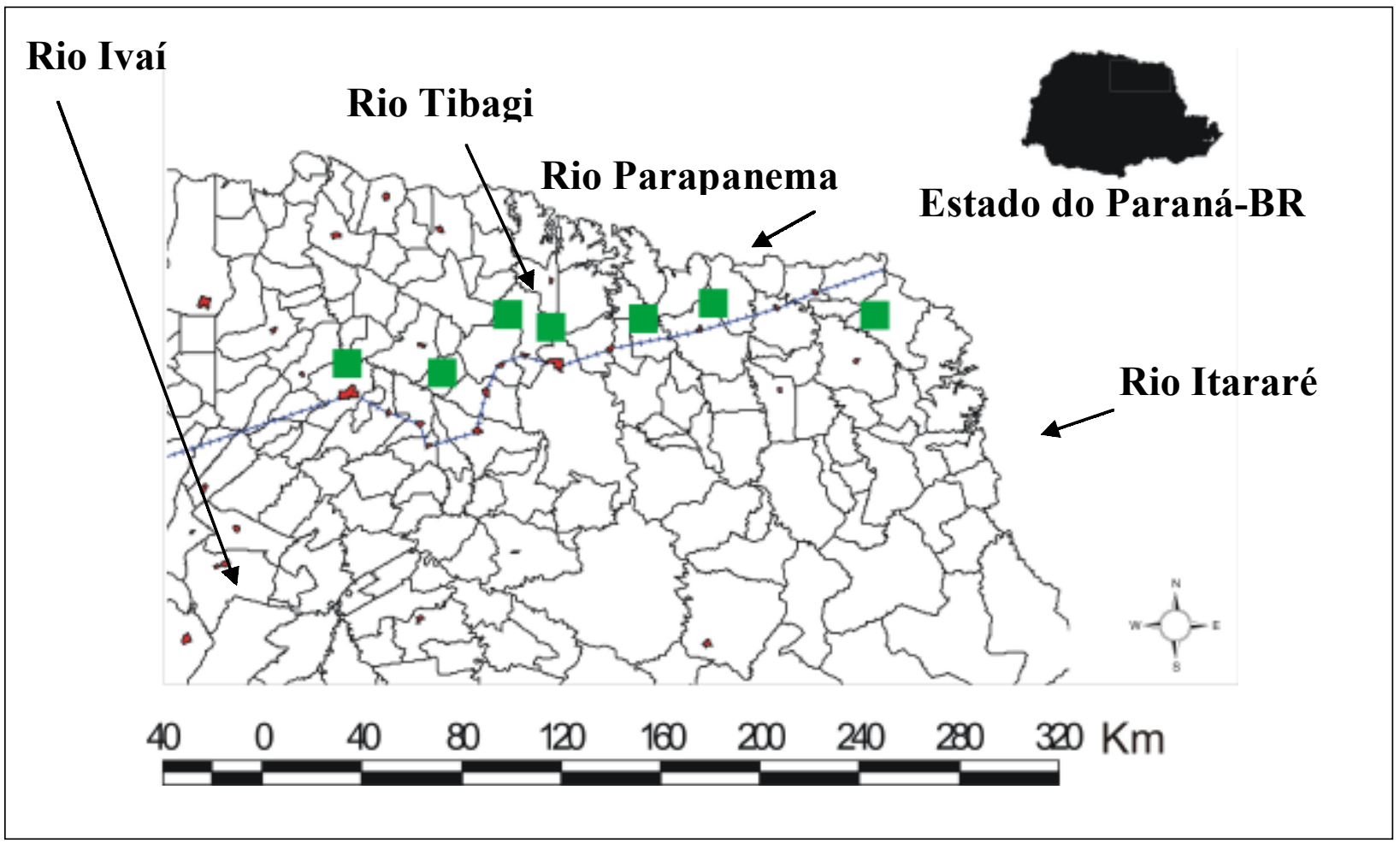

Figura 1 - Mapa da área de estudo. 
Os tipos de solos que predominam nas regiões são: Terra Roxa Estruturada, Latossolo Roxo e Litossolos (EMBRAPA, 1981; IPARDES, 1993). A altitude regional varia de 380 a $700 \mathrm{~m}$, com relevo ondulado a suavemente ondulado (FERREIRA, 1996). O clima é do tipo $C f a$, e, periodicamente variando ao $C w a$, segundo classificação de Köppen, com verão quente e geadas pouco freqüentes, não há estação seca definida, embora haja tendência de concentração das chuvas nos meses de verão. A média das temperaturas supera os $22^{\circ} \mathrm{C}$ nos meses mais quentes; nos meses mais frios, é inferior a $18^{\circ} \mathrm{C}$ (MAACK, 1981). A cobertura vegetal original, segundo o Instituto Brasileiro de Geografia e Estatística, é a Região da Floresta Estacional Semidecidual - Floresta Tropical Subcaducifólia - que, outrora, recobria todo o Norte do Paraná (IBGE, 1998)

Utilizaram-se imagens de satélite LANDSAT/ TM-5, bandas 1,2,3,4,5 e 7, em formato digital, Órbita 221 e 222/ Ponto $76+6$ segundos com nível de correção 5, datadas de 07/06/2000 e 19/11/1999, resolução 30 metros. As informações cartográficas foram extraídas de cartas planialtimétricas na escala de 1:50.000 e 1:100.000, produzidas pelo Exército Brasileiro - Brasil (1973) e IBGE (1970).

O processamento digital das imagens (PDI) foi feito no laboratório de Ecologia da Paisagem da Universidade Estadual de Londrina (UEL). Utilizando-se um microcomputador, Pentium 350 e o aplicativo, IDRISI for Windows. A quantificação da estrutura da paisagem e/ou padrão espacial foi obtida através do Programa Fragstats, - índice e/ou métricas de disposição - um software desenvolvido por McGarigal e Marks em 1994, que calcula a estrutura da paisagem usando mais de 50 métricas (SÁ VOLOTÃO, 1998).

Chegou-se ao local dos transectos por amostragem sistemática, com transecto na direção nordeste para sudoeste. Selecionou-se sete sub-regiões (Figura 1): 1- Jacarezinho (0 km), 2-Santa Mariana (30 km), 3- Uraí (60 km), 4- Londrina (90 km), 5- Cambé (120 km), 6- Sabáudia (150 km) e 7-
Maringá (180 km), distantes em 1.000 pixels - @30 $\mathrm{km}$ - entre si. A fim de se evitar sobreposição, os tamanhos das unidades amostram foi de 10.000 ha, somando 70.000 ha a área total da Tabela 1.

A disposição do transecto de forma arbitraria evitou a proximidade de rodovias e espaços urbanos, áreas que, devido à alta densidade humana e à presença de edifícios comercias e industriais, geram grande perturbação antrópica ao ambiente (RODRIGUES, 1993).

De acordo com Rodrigues (1998), determinou-se que a menor superfície de fragmento florestal estudada nas áreas amostradas seria de 1 ha, em função da resolução espacial do pixel de $30 \mathrm{~m}$ (sistema sensores Thematic Mapper-TM); também se adotou a distância de $35 \mathrm{~m}$ para definir a borda do fragmento.

Para a classificação das imagens, utilizou-se de vários módulos existentes no ambiente IDRISI for Windows (EASTMAN, 1992), os quais estão esquematicamente representados na (Figura 2).

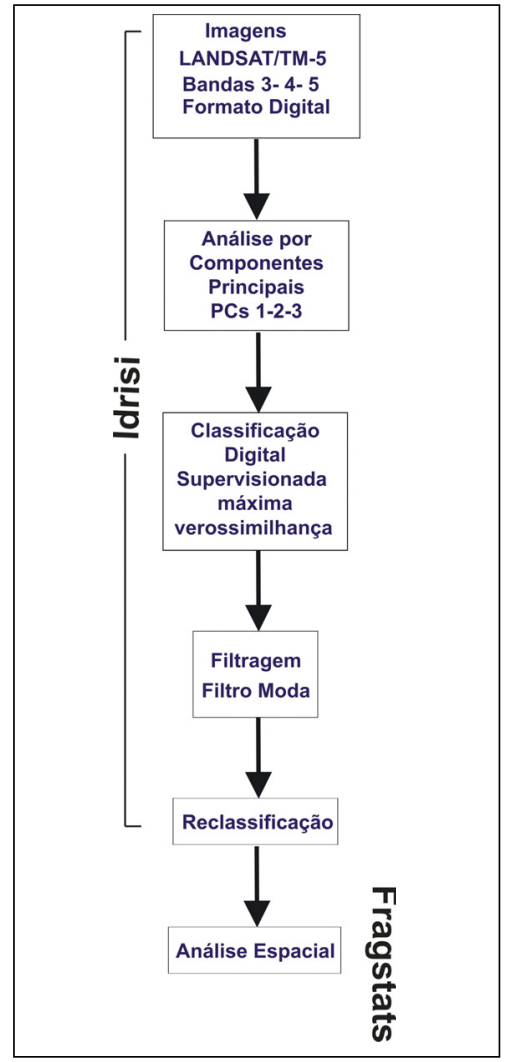

Figura 2 - Principais módulos do Idrisi for Windows utilizados na obtenção dos fragmentos florestais. 
Para redução da dimensionalidade das 6 bandas LANDSAT-TM em PCs 1-2-3, utilizou-se da Análise por Componentes Principais, cuja a principal tarefa pode ser resumida da seguinte forma: dadas $\mathrm{N}$ imagens brutas - sem qualquer tipo de processamento são analisadas as correlações entre elas, produzindo um novo conjunto de $\mathrm{N}$ novas imagens, sem nenhuma correlação entre si. De modo geral, esse novo conjunto de imagens terá as seguintes características: a primeira delas chamada de primeira Componente Principal ou PC 1, irá conter as informações que são comuns a todas as $\mathrm{N}$ bandas originais; a segunda PC irá conter a feição espectral mais significante do conjunto e assim sucessivamente as PCs de ordem mais alta irão conter feições espectrais cada vez menos significantes, até a última PC, que concentrará então a informação que sobrar ou seja os ruídos.

Utilizou-se a classificação digital supervisionada, onde os algoritmos são desenhados para enquadrar os pixels nas classes de interesse. Para a classificação foi empregado o Método da Máxima Verossimilhança-MAXVER, que se baseia no cálculo da distância estatística entre cada pixel e a média dos níveis de cinza da classe previamente definida a partir de amostras de treinamento (DUTRA et al. 1981).

No processo de filtragem utilizou-se Filtro de Moda. Este tipo de filtro é bastante útil para "limpar" pixel isolados em imagens representando resultados de classificação estatística multi-espectral.

As classes escolhidas na reclassificação das imagens foram: fragmentos-florestais identificados como número 1 (um) e não-fragmentos-florestais identificados como número 0 (zero).

Os fatores espaciais da paisagem considerados na análise estatística da quantificação da estrutura da paisagem obtida através do programa Fragstats foram os seguintes: (i) número de fragmentos, (ii) relação área/tamanho, (iii) formato, e, (iv) proximidade dos fragmentos. Estes foram submetidos ao teste não paramétrico de correlação de coeficiente de Kendall's rank,t (SOKALL; ROHLF, 1995; SPRENT, 1989).

O índice área/tamanho dos fragmentos é a base do conhecimento da paisagem. São muito úteis em estudos ecológicos, uma vez que a riqueza e abundância de certas espécies dependem, para existir, das dimensões dos fragmentos existentes na paisagem (SÁ VOLOTÃO, 1998).

O formato do fragmento é uma característica importante no estudo da dinâmica e estrutura dos fragmentos florestais (SILVA et al. 1997).

Para o fragmento de floresta de formato circular, o cálculo matricial tem índice matemático mínimo igual a 0.88. Entretanto o cálculo matricial leva em conta os cantos do pixel e presume os quadrados, fazendo com que grandes fragmentos circulares, tenham valor próximo de 1.13 , enquanto que em formatos retangulares com lados L e $2 \mathrm{~L}$; L e $10 \mathrm{~L}$; L e $100 \mathrm{~L}$ os valores dos índices são respectivamente iguais a 1.06, 1.74 e 5,05. Quanto mais recortado e menor a área do fragmento, maior será o valor do índice (SÁ VOLOTÃO, 1998).

A proximidade entre os fragmentos florestais é importante para os processos ecológicos, estando implícito, em seus resultados, o grau de isolamento dos fragmentos (SÁ VOLOTÃO, 1998).

Tal grau de isolamento age negativamente na riqueza ao diminuir a taxa e/ou potencial de imigração ou recolonização (METZGER, 1999).

Para o índice de proximidade dos fragmentos, quanto maior o valor do índice, maior será à distância entre fragmentos.

\section{Resultados e Discussão}

$\mathrm{Na}$ Tabela 1 encontram-se os valores calculados de Kendall's t para os índices de paisagem e na Tabela 2 estão apresentadas as imagens classificadas bem como os índices de paisagens. 
Tabela 1 - Coeficiente de Correlação de Kendall's t /prob $>|\mathrm{R}|$ inferior Ho $=/ \mathrm{N}=7$, calculados para os índices de paisagem.

\begin{tabular}{cccccc}
\hline & Distância & $\begin{array}{c}\text { Número de } \\
\text { Fragmentos }\end{array}$ & $\begin{array}{c}\text { Área/Tamanho dos } \\
\text { Fragmentos }\end{array}$ & $\begin{array}{c}\text { Forma dos } \\
\text { Fragmentos }\end{array}$ & $\begin{array}{c}\text { Proximidade dos } \\
\text { Fragmentos }\end{array}$ \\
\hline \multirow{2}{*}{ Distância } & $\tau 1.0000$ & $\tau 0.19518$ & $\tau 0.14286$ & $\tau-0.14286$ & $\tau 0.04762$ \\
& $\mathrm{p} 0.0$ & $\mathrm{p} 0.5434$ & $\mathrm{p} 0.6523$ & $\mathrm{p} 0.6523$ & $\mathrm{p} 0.8806$ \\
\hline
\end{tabular}

$(\tau$ de kendall's $=p>5 \%)$.

Tabela 2 - Índices da Paisagem obtidas através do Programa Fragstats, das Imagens classificadas LANDSAT/TM-5.

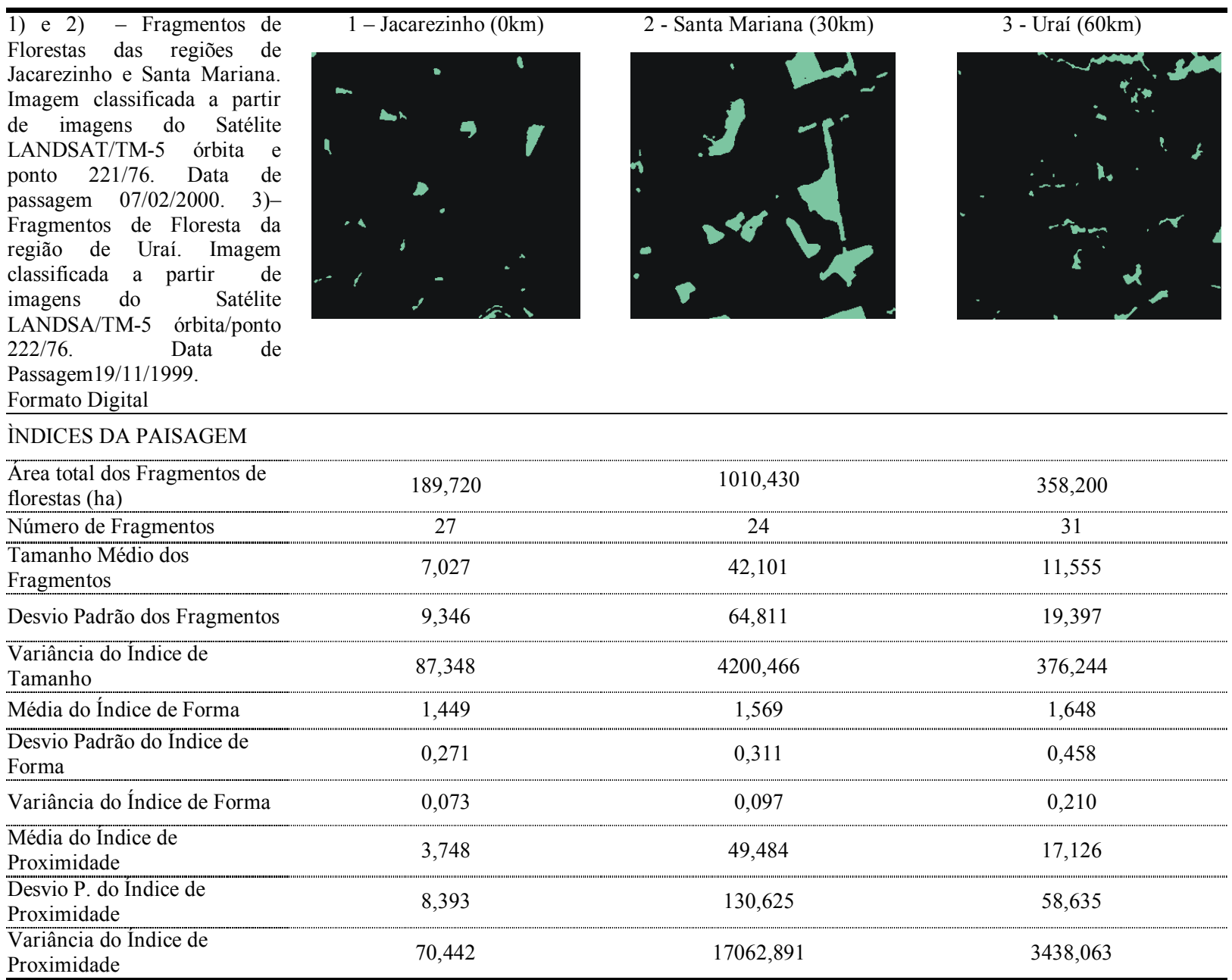


(continuação Tabela 2)

\begin{tabular}{l}
\hline 4), 5), 6) e 7) - Fragmentos \\
Florestais das regiões de \\
Londrina, Cambé, Sabáudia \\
e Maringá. \\
classificada a partir de \\
imagens do \\
LANDSAT/TM-5 órbita e \\
ponto 222/76. Data de \\
passagem \\
Formato Digital.
\end{tabular}
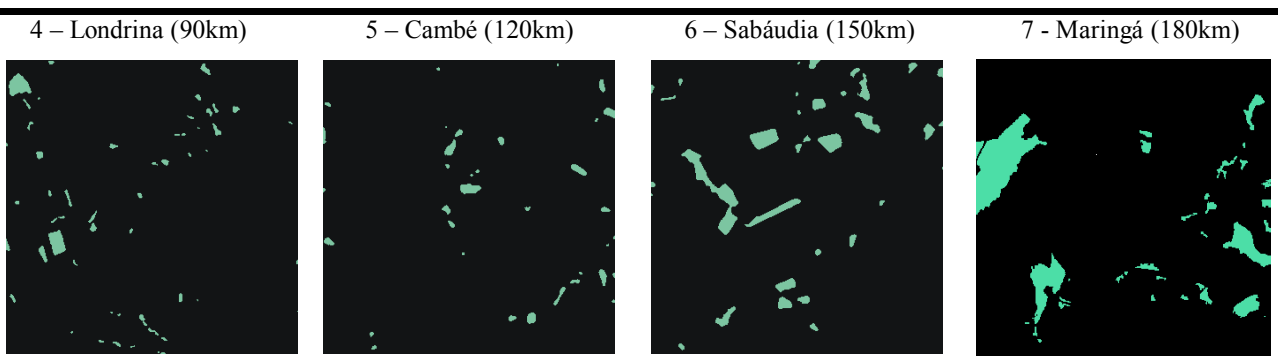

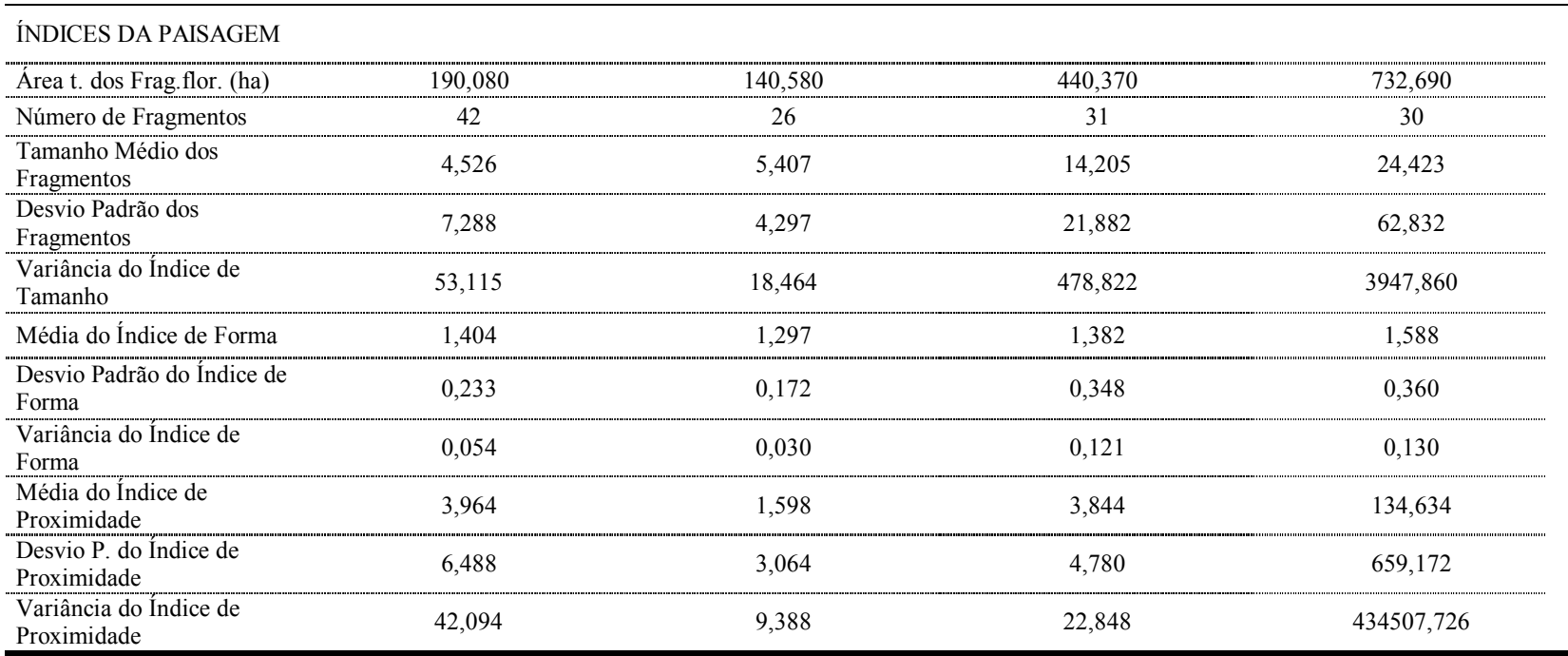

\section{Número de Fragmentos}

Nas três amostras localizadas no Norte Velho, foram encontrados 82 fragmentos, enquanto que nas quatro amostras do Norte Novo, encontrou-se 129 fragmentos. Londrina tem o maior número de fragmentos (Figura 3). Nas demais amostras existem um equilíbrio entre os números de fragmentos. O número de fragmentos não defini totalmente a estrutura espacial, mas, certamente pode-se considerar que ele representa parte da configuração da paisagem.

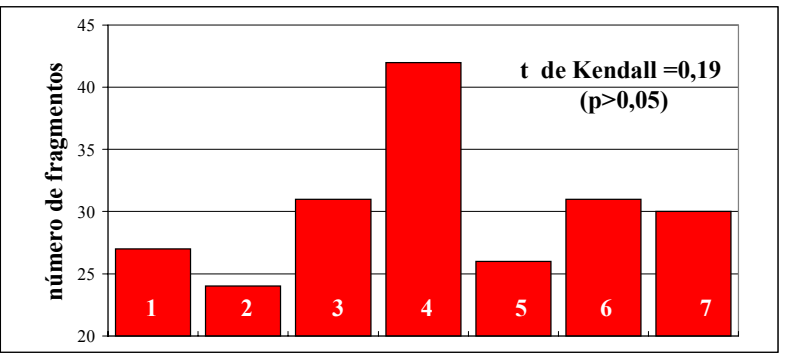

Figura 3 - Número de fragmentos encontrados em: 1Jacarezinho $(0 \mathrm{~km})$, 2-Santa Mariana $(30 \mathrm{~km}), 3$ - Uraí $(60 \mathrm{~km})$, 4- Londrina $(90 \mathrm{~km}), 5$ - Cambé $(120 \mathrm{~km}), 6$ Sabáudia $(150 \mathrm{~km})$ e 7 - Maringá $(180 \mathrm{~km})$. 


\section{Área/Tamanho dos Fragmentos}

No Norte Velho, a área de cobertura vegetal por fragmentos de floresta é de 1.558,35 ha esse valor é igual a $5,19 \%$ dos 30.000 ha amostrados. Santa Mariana tem 1.010,43 ha de cobertura florestal em 24 fragmentos. Esse percentual elevado de 64,83\% do total da área de florestas do Norte Velho prejudicou, a avaliação do atual estado da degradação antrópica da paisagem da região.

Nas amostras da região Norte Novo, a cobertura florestal representada por fragmentos de florestas é de 1.503,72 ha, 3,75\% da área amostrada. Maringá, tem a maior área de fragmentos florestais, 732,69 ha. Esse valor representa 1,83\% da cobertura florestal da região. Também nessa região encontramos os menores valores de cobertura vegetal por fragmentos de florestas. Essa constatação está diretamente relacionada ao processo rápido de colonização do Norte Novo que começou em Londrina em 1930, seguindo para oeste, com a fundação de Maringá em 1947, onde as matas cederam lugar às fazendas e povoados. Sendo que as menores médias de área/ tamanho de fragmentos florestais foram encontradas, em Londrina, com 190,58 ha e Cambé, com 140,37 ha. Esses valores são devidos ao uso intensivo do solo em práticas agrícolas, aliadas à urbanização crescente da região, o que poderá implicar na eliminação destes fragmentos. Oliveira et al. (1997) observaram que remanescentes tão diminutos não têm capacidade de proteger a biodiversidade, podendo rapidamente transformar-se em hábitat-borda.

A relação área/tamanho dos fragmentos, apresentados na Figura 4, mostra que dos oitenta e dois fragmentos encontrados no Norte Velho, existem apenas sete fragmentos com áreas superiores a 50 ha, dos quais dois apresentam área de 140 ha, um de 160 ha e um de 250 ha. Estes quatro fragmentos estão localizados em Santa Mariana.

No Norte Novo, dos cento e vinte nove fragmentos encontrados, a grande maioria tem sua área entre 1,08 e 24 ha. Dos quatro maiores fragmentos, um encontra-se em Sabáudia, com 113 ha, e três encontram-se em Maringá, (90 ha, 140 ha e 326,43 ha).

A diferença indica que existe uma tendência de que as amostras com grande área de fragmentos florestais tenham a média de tamanho de fragmentos elevada. Essa constatação está em conformidade com os registros de Rodrigues (1993).

Para Metzger (1999) a diminuição da área dos fragmentos leva à redução da diversidade biológica. Para o autor, os tipos de borda na paisagem aumentam à medida que a textura do mosaico se torna menor, ou seja, quando o tamanho médio dos fragmentos diminui.

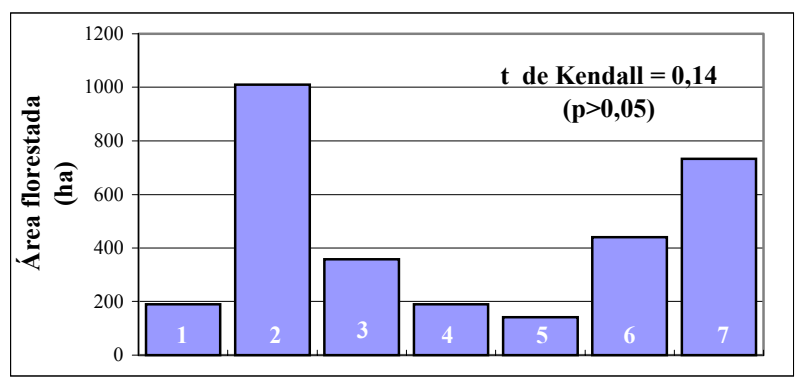

Figura 4 - Área/tamanho em ha dos fragmentos encontrados em: 1- Jacarezinho (0 km), 2-Santa Mariana (30 $\mathrm{km})$, 3- Uraí $(60 \mathrm{~km})$, 4- Londrina $(90 \mathrm{~km})$, 5- Cambé $(120 \mathrm{~km}), 6$ - Sabáudia $(150 \mathrm{~km})$ e 7 - Maringá $(180 \mathrm{~km})$.

\section{Forma dos Fragmentos}

A Figura 5 evidencia que os fragmentos florestais localizados no Norte Velho possuem formato retangular, com exceção da amostra de Jacarezinho, onde os fragmentos possuem índices mais próximos de 1 , sendo estes de forma circular. Na região do Norte Novo, os fragmentos apresentam formato mais arredondado, apenas na região de Maringá, os fragmentos florestais têm formato retangular em sua totalidade. Onde os fragmentos são maiores, eles tendem também a ser mais alongado. $O$ fato da maioria dos fragmentos florestais do Norte Novo apresentar índices de circularidade próximo de 1 não significa que estão isentos do efeito de borda, uma vez que os fragmentos apresentam áreas diminutas. 


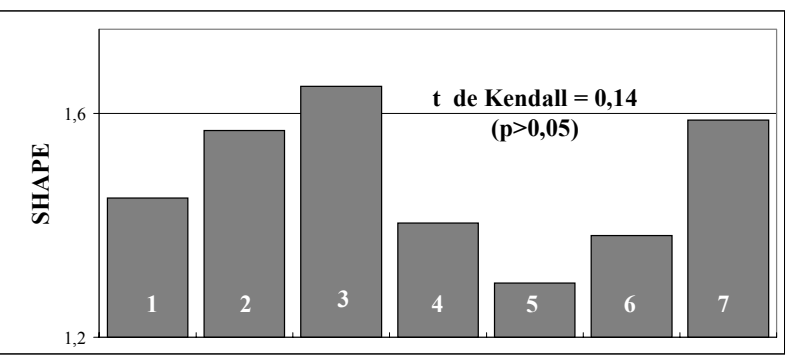

Figura 5 - Forma dos fragmentos localizados em: 1Jacarezinho $(0 \mathrm{~km}), 2$-Santa Mariana $(30 \mathrm{~km}), 3$ - Uraí $(60 \mathrm{~km}), 4$ - Londrina $(90 \mathrm{~km}), 5$ - Cambé $(120 \mathrm{~km}), 6$ Sabáudia $(150 \mathrm{~km})$ e 7- Maringá $(180 \mathrm{~km})$.

\section{Proximidade dos Fragmentos}

$\mathrm{O}$ índice de proximidade encontrado mostra que a distância entre os fragmentos florestais é maior no Norte Velho - notadamente em Santa Mariana - do que no Norte Novo (Figura 6), com exceção da região de Maringá, que possui um fragmento isolado dos demais.

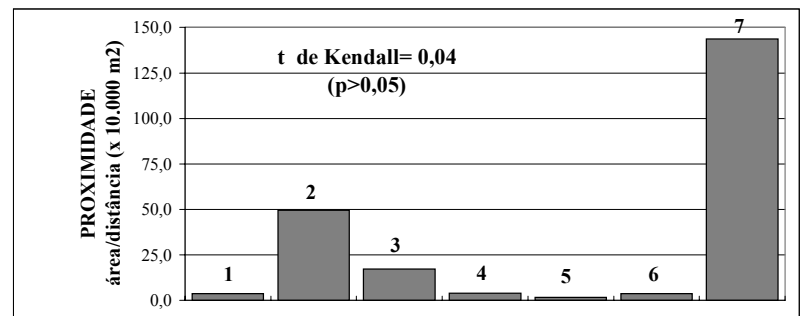

Figura 6 - Proximidade dos fragmentos localizados em: 1- Jacarezinho (0 km), 2-Santa Mariana (30 km), 3- Uraí $(60 \mathrm{~km}), 4$ - Londrina $(90 \mathrm{~km}), 5$ - Cambé $(120 \mathrm{~km}), 6$ Sabáudia $(150 \mathrm{~km})$ e 7- Maringá (180 km).

\section{Conclusões}

1- A hipótese inicial levantada deve ser refutada. Há no entanto, que considerar a desuniformidade das áreas analisadas. $\mathrm{Na}$ eventual continuidade da pesquisa sugere-se a repetição com um número maior de amostras.

2- Ao contrário do que ocorreu no Norte Velho colonizado em meados do Século XIX e inicio do Século XX, onde predominava a grande proprie- dade como ocorria em São Paulo e Minas Gerais, de onde provieram a maioria de seus colonizadores, o Norte Novo teve um processo de colonização organizado e um desmatamento rápido, onde a área vendida pela colonizadora era imediatamente desmatada, influenciando a forma, o tamanho, e a proximidade dos fragmentos, dando origem a paisagens homogêneas, tornando-as mais suscetíveis a danos em larga escala.

\section{Referências}

ARAGAKI, S. Floristica e estrutura de trecho remanescente de floresta no planalto paulistano. 1997. Dissertação (Mestrado em Ecologia) - Universidade de São Paulo, São Paulo.

BRASIL. Ministério do Exército. Divisão de Serviços Geográficos. Cartas planialtimétricas. Brasília, 1973. Escala 1:100. 000.

CANCIÁN, N. A. Cafeicultura paranaense (1900-1970): estudo de conjuntura. 1977. Tese (Doutorado) - Universidade de São Paulo, São Paulo.

CARVALHO, M. S. de. A pequena produção de café no Paraná. 1991. Tese (Doutorado)-Faculdade de Filosofia, Letras e Ciências Humanas, Universidade de São Paulo, São Paulo.

DUTRA, L. V. et al. Análise automática de imagens multiespetrais. São José dos Campos: INPE, 1981.

EASTMAN, J. R. Idrisi : user's guide. Worcester: Clark University, 1992.

EMBRAPA. Levantamento e reconhecimento de solos do estado do Paraná: (escala $1: 600.000$ ). Rio de Janeiro, 1981.

FERREIRA, J. C. V. O Paraná e seus municípios. Maringá: Memória Brasileira, 1996.

FUNDAÇÃO S.O.S. MATA ATLÂNTICA / INPE. Atlas da evolução dos remanescentes florestais e ecossistemas associados da Mata Atlântica 1990 - 1995. Disponível em $<$ http://www.sosmatatlantica.org.br $>$. Acesso em: 03 mar. 2001..

IBGE. Anuário Estatístico do Brasil. Rio de Janeiro, 1998.

IBGE. Cartas planialtimétricas. Rio de Janeiro, 1970. Escala 1:50.000

IPARDES. Cobertura florestal e consumo de madeira, lenha e carvão nas microrregiões de Londrina, Maringá e Paranavaí. Curitiba, 1993. 
ISHIHATA, L. Bases para seleção de áreas prioritárias para a implantação de unidades de conservação em regiões fragmentadas. 1999. Dissertação (Mestrado em Ciência Ambiental) - Universidade de São Paulo, São Paulo.

LUZ, F. O fenômeno urbano numa zona pioneira: 1980. Dissertação (Mestrado) - Universidade de São Paulo, São Paulo.

MAACK, R. Geografia física do estado do Paraná. Curitiba: BDP/UFPR/IBPT, 1981.

METZGER, J. P. Estrutura da paisagem e fragmentação: análise bibliográfica. Anais da Academia Brasileira de Ciências, Rio de Janeiro, v.71, n. 3-I, p.445-463, 1999.

OLIVEIRA, L. M. T. et al. Diagnóstico de fragmentos florestais nativos, em nível de paisagem, Eunápolis-BA. Revista Árvore, Viçosa, v.21, n.4, p.511-520, 1997.

PADIS, P. C. Formação de uma economia periférica: o caso do Paraná. São José dos Campos: Hucitec, 1981.

RODRIGUES, E. Ecologia de fragmentos florestais no gradiente de urbano de Londrina. 1993. Dissertação (Mestrado em ) - Universidade de São Paulo, São Paulo.

RODRIGUES, E. Efeitos de bordas em fragmentos de Londrina. Cadernos da Biodiversidade, Maringá, v.1, n.2, p.1-6, dez. 1998.

RODRIGUES, E; CAMARA, C. D.; DIAS. A. T. Comparação entre os padrões espaciais de remanescentes florestais no gradiente urbano de Londrina. Semina, Londrina, v.16, n.1, p.34-39, mar. 1995.

SÁ VOLOTÃO, C. F. Trabalho de análise espacial métrica do fragstats. São José dos Campos: INPE, 1998.
SILVA, E. et al. Diagnóstico de fragmentos florestais nativos, em nível de paisagem, Itabira-MG. Revista Árvore, Viçosa, v.21, n.4, p.521-526, 1997.

SOKAL, R. R.; ROHLF, F. J. Biometry: the principles and practice of statistics in biological research. New York: W. H Freeman and Company, 1995.

SPRENT, P. Applied nonparametric statistical methods. London: Chapman and Hall, 1989.

TABANEZ, A. A. J.; VIANA, V. M.; DIAS, A. da S. Conseqüências da fragmentação e do efeito de borda sobre a estrutura, diversidade e sustentabilidade de um fragmento de floresta de planalto de Piracicaba, SP. Revista Brasileira de Biologia, Piracicaba, v.57, n.1, p.47-60, fev. 1997.

VIANA, V. M. Biologia de manejo de fragmentos de florestas naturais. In: CONGRESSO FLORESTAL BRASILEIRO, 6., 1990, Campos do Jordão. Anais... Campos do Jordão: Sociedade Brasileira de Silvicultura/Sociedade Brasileira de Engenheiros Florestais, 1990. p.155.

VIANA, V. M.; TABANEZ, A. A. J.; MARTINEZ, J. L. A. Restauração e manejo de fragmentos florestais. In: CONGRESSO NACIONAL SOBRE ESSÊNCIAS NATIVAS, 2., 1992, São Paulo. Anais... São Paulo: Instituto Florestal de São Paulo, 1992. p.400-407.

ZANI, A. C. Arquitetura de madeira: reconhecimento de uma cultura arquitetônica norteparanaense -1930 - 1970. 1997. Tese (Doutorado) - Faculdade de Arquitetura e Urbanismo. Universidade de São Paulo, São Paulo. 